\title{
Product Pharmaceutical Product Expiration Date
}

National Cancer Institute

\section{Source}

National Cancer Institute. Product Pharmaceutical Product Expiration Date. NCI

Thesaurus. Code C94029.

The date (and time), assigned by the manufacturer, on which the product should not be used. 